\title{
FITOTECNIA
}

\section{PRODUTIVIDADE DO CAFÉ APOATÃ EM CONSÓRCIO COM LEGUMINOSAS NA REGIÃO DA ALTA PAULISTA ${ }^{(1)}$}

\author{
EDISON MARTINS PAULO ${ }^{(2)}$; RONALDO SEVERIANO BERTON ${ }^{(3)}$; \\ JOSÉ CARLOS CAVICHIOLI ${ }^{(2)}$; EDUARDO ANTONIO BULISANI ${ }^{(4)}$; \\ FRANCISCO SEIITI KASAI ${ }^{(2)}$
}

\begin{abstract}
RESUMO
Avaliou-se, no Núcleo de Agronomia da Alta Paulista, no período de 1991 a 1993, a produção de café Apoatã IAC 2258 (Coffea canephora Pierre) submetido ao plantio intercalar dos adubos verdes: crotalária júncea (Crotalaria juncea L.), crotalária espectabilis (Crotalaria spectabilis Roth.), mucuna-anã (Stizolobium deeringeanum Bort.), soja IAC 9 [Glycine max (L.) Merrill] e guandu [Cajanus cajan (L.) Millsp.], incorporados no seu florescimento. As leguminosas foram plantadas a $50 \mathrm{~cm}$ da projeção da copa das plantas de café. Adotou-se o delineamento estatístico de blocos ao acaso com cinco repetições. Os resultados mostraram que o guandu e a crotalária júncea reduziram a produção de café, e o guandu, a altura e o diâmetro do caule do cafeeiro, o que não ocorreu com as demais leguminosas. As maiores quantidades de fitomassa seca foram produzidas por guandu e crotalária júncea respectivamente. A produção de café correlacionou-se inversamente com a fitomassa seca das leguminosas e, positivamente, com a altura e o diâmetro do caule do cafeeiro.
\end{abstract}

Palavras-chave: café, Coffea canephora, adubação verde, leguminosa, consórcio, cultura intercalar.

\section{ABSTRACT \\ COFFEE PRODUCTIVITY DURING INTERCROPPING WITH FIVE LEGUMINOUS SPECIES IN THE WESTERN REGION OF SÃO PAULO STATE, BRAZIL}

Coffee (Coffea canephora Pierre) productivity was evaluated during three years of intercropping with five leguminous species: sunn hemp (Crotalaria juncea L.), Crotalaria spectabilis Roth., dwarf velvet bean (Stizolobium deeringeanum Bort.), soybean [Glycine max (L.) Merryl] and pigeon pea [Cajanus cajan (L.) Millsp.] in the western region of São Paulo State, from 1991 to 1993. Leguminous species were seeded $50 \mathrm{~cm}$ far from coffee shoot and incorporated at flowering stage. The treatments were arranged in a randomized complete block design with five replicates. Coffee yield was not affected when Crotalaria spectabilis, dwarf velvet bean and soya bean IAC 9 were used as interrow crop, but it was significantly decreased for pigeon pea and sunn hemp treatments. Linear correlation analysis showed that coffee yield was inversely correlated with leguminous dry biomass and positively correlated with coffee shoot height and stem diameter at the harvest year.

Key words: coffee, Coffea canephora, green manuring, leguminous species, intercroping.

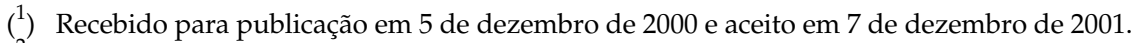

$\left(^{2}\right)$ Núcleo de Agronomia da Alta Paulista, Instituto Agronômico (IAC), Caixa Postal 191, 17800-000 Adamantina (SP). E-mail: ed.paulo@uol.com.br

$\left({ }^{3}\right)$ Centro de Solos e Recursos Agroambientais, Instituto Agronômico (IAC), Caixa Postal 28, 13001-970 Campinas (SP). E-mail: rsberton@barao.iac.br

( $\left.{ }^{4}\right)$ Centro de Plantas Graníferas, Instituto Agronômico (IAC), Caixa Postal 28, 13001-970 Campinas (SP). 


\section{INTRODUÇÃO}

O café robusta (Coffea canephora Pierre) apresenta tolerância aos nematóides, à ferrugem, ao bicho-mineiro e possui linhagens de alta produtividade (VEGRO et al., 1996) o que, associado à sua adaptação a baixas altitudes e temperaturas elevadas, leva a considerar sua recomendação a regiões julgadas marginais para o café arábica. No Oeste paulista, essas condições são normalmente encontradas em solos empobrecidos conseqüência da falta de aplicação de práticas adequadas de conservação do solo.

A adubação verde é uma prática conservacionista citada por muitos autores (LOMBARDI-NETO et al., 1976a, 1976b; DECHEN et al., 1981; MiYASAKA et al., 1983 e IGUe, 1984), sendo considerada como uma das mais eficientes no controle de erosão (LOMBARDI-NETO et al., 1976a). A sua utilização melhora as condições físicas ( IGUe, 1984; BERTONI e LOMBARDi-NETO, 1985), químicas e biológicas (IGUE, 1984), recuperando a fertilidade do solo.

As leguminosas são as plantas preferidas para a formação da matéria orgânica do solo em virtude da grande massa produzida por unidade de área, da sua riqueza em elementos minerais, do seu sistema radicular bastante ramificado e profundo, da capacidade de mobilização dos nutrientes do solo e, principalmente, da possibilidade de aproveitamento do nitrogênio atmosférico (Malavolta, 1967). Essas plantas podem, também, ser utilizadas para proteger os cafeeiros contra os ventos (MelLes e SiLva, 1978).

O uso da adubação verde intercalada ao café arábica (Coffea arabica L.) tem sido, ao longo do tempo, uma prática bastante controvertida. Relacionada à produtividade do cafeeiro, a adubação verde pode não beneficiar (FRANCO et al., 1960; FRANCO e LAZZARINI, 1967; LaZZARINI e Neme, 1967; ReIS e ARRUda, 1974) ou ser prejudicial (LombARDi-Neto et al., 1976a; MelLES et al., 1979; ReIs e ARRUDA, 1980). Já se observou, também, acréscimos da produção, após prejuízos nos períodos iniciais da aplicação dessa prática (FRAGA e CONAGIN, 1956).

O presente trabalho objetivou estudar a produção e o crescimento do café Apoatã IAC 2258 submetido à adubação verde com espécies de leguminosas.

\section{MATERIAL E MÉTODOS}

O experimento foi desenvolvido no Núcleo de Agronomia da Alta Paulista, no período de 1991 a 1993, com café Apoatã IAC 2258, um ano após o plantio. Adotou-se o delineamento estatístico de blocos ao acaso, com seis tratamentos e cinco repetições.
Aos tratamentos corresponderam as espécies: mucuna-anã (Stizolobium deeringeanum Bort.), crotalária júncea (Crotalaria juncea L.), crotalária espectabilis (Crotalaria spectabilis Roth.), guandu [Cajanus cajan (L.) Millsp.] e soja IAC-9 [Glycine max (L.) Merrill], plantadas intercaladamente à cultura do café, e uma testemunha sem plantio intercalar. A parcela experimental constituiu-se de 16 covas com dois cafeeiros cada uma, dispostas em quatro linhas de plantio, no espaçamento de 4,0 × 2,0 m, considerando-se úteis as quatro covas centrais. Adubaram-se as covas, no plantio, com $250 \mathrm{~g}$ de superfosfato simples e $30 \mathrm{~g}$ de cloreto de potássio.

As leguminosas foram semeadas a $50 \mathrm{~cm}$ da projeção da copa do cafeeiro e em sulcos espaçados de $50 \mathrm{~cm}$ entre si, os quais não receberam adubação. Repetiu-se esse procedimento no período de outubro a novembro de cada ano da experimentação. A densidade de semeadura e os tratos culturais seguiram a recomendação técnica para cada leguminosa (PEDroJúNIOR et al., 1987). Efetuou-se o corte dos adubos verdes na fase de pleno florescimento-frutificação das espécies em estudo e incorporou-se a fitomassa ao solo com grade ou enxada rotativa. Nessa ocasião, avaliaram-se a fitomassa verde e seca das leguminosas, a altura das plantas de cafée, a $30 \mathrm{~cm}$ do solo, o diâmetro dos caules dos cafeeiros. A fitomassa foi amostrada em 4 pontos de $0,5 \mathrm{~m}$ na linha da semeadura, casualizadamente na área útil das parcelas, e seca em estufa a $65^{\circ} \mathrm{C}$ até massa constante.

Coletaram-se anualmente amostras de solo à profundidade de 0-20 cm, 60 dias após a incorporação das leguminosas, analisadas para fins de fertilidade, segundo o método descrito por RAIJ e QUAGGIO (1983).

\section{RESULTADOS E DISCUSSÃO}

A produção de café em 1991 e 1992 foi inexpressiva. Para efeito de análise estatística consideraram-se os resultados da primeira produção efetiva, que ocorreu em 1993, e o total do triênio (Quadro 1). Em 1993, a produção de café Apoatã nos tratamentos com crotalária júncea, guandu e soja foi significativamente menor que a da testemunha, e a produção no tratamento com soja equivaleu à da crotalária espectabilis e mucuna-anã. No total do triênio, nos tratamentos com crotalária júncea e guandu, a produção de café foi menor que a da testemunha. Os resultados obtidos na testemunha não diferiram dos observados nos demais adubos verdes.

Os resultados do tratamento com soja estão de acordo com os de Franco et al. (1960) e FrANCO e LAZZARINI (1967), que não verificaram efeito na pro- 
Quadro 1. Produção de café Apoatã IAC 2258 submetido ao plantio intercalar de adubos verdes (médias de cinco repetições)

\begin{tabular}{|c|c|c|}
\hline \multirow{2}{*}{ Tratamento } & \multicolumn{2}{|c|}{ Produção de café em coco } \\
\hline & 1993 & Total $^{(1)}$ \\
\hline & \multicolumn{2}{|c|}{ - kg.ha ${ }^{-1}$} \\
\hline Crotalária espectabilis & $4.622 \mathrm{ab}$ & $4.738 \mathrm{ab}$ \\
\hline Crotalária júncea & $3.825 \mathrm{~b}$ & $3.832 \mathrm{~b}$ \\
\hline Guandu & $406 \mathrm{c}$ & $406 \mathrm{c}$ \\
\hline Mucuna-anã & $5.097 \mathrm{ab}$ & $5.378 \mathrm{ab}$ \\
\hline Soja & $4.397 \mathrm{~b}$ & $4.518 \mathrm{ab}$ \\
\hline Testemunha & $6.015 \mathrm{a}$ & $6.164 \mathrm{a}$ \\
\hline $\mathrm{F}$ & $14,8^{* *}$ & $13,8^{* *}$ \\
\hline CV $(\%)$ & 28 & 29 \\
\hline
\end{tabular}

(1) Soma da catação de frutos dos anos de 1991,1992 e a primeira produção efetiva de café em 1993. Médias seguidas por letras distintas, na vertical, diferem, entre si, pelo teste de Duncan a $5 \%$. **: Significativo ao nível de $1 \%$.

dução de café com o uso dessa leguminosa sem a incorporação ao solo. Diferem, contudo, dos obtidos por Melles et al. (1979), que avaliaram a colheita dos grãos de café utilizando quatro a cinco linhas de soja como cultura intercalar.

A diminuição da produção de café observada nos tratamentos com guandu e crotalária júncea não foi verificada por LAZZARINI e NEME (1967), após cultivarem o cafeeiro por quatro anos em consórcio com essas leguminosas. A diferença nos resultados devese, provavelmente, ao fato de que aquele experimento foi realizado em lavouras velhas e com o uso de apenas duas linhas das leguminosas entre as do cafeeiro. Outro fator que pode ter influenciado negativamente a produção foi a incorporação dos adubos verdes por grade ou enxada rotativa, com provável corte de raízes superficiais das plantas de café.

InFORZATO e ReIs (1963) observaram que cerca de $90 \%$ das raízes dos cafeeiros Mundo Novo encontram-se na camada de $50 \mathrm{~cm}, 66 \%$ na de $30 \mathrm{~cm}$ e $28 \%$ até $15 \mathrm{~cm}$ de profundidade do solo. Em Coffea canephora, 94\% das raízes estão na camada de $60 \mathrm{~cm}$ (Batistela-Sobrinho e Matiello, 1987) e as maiores quantidades de radicelas são encontradas na faixa mais superficial do solo (MATIELLO et al., 1996).

O total da fitomassa verde produzida pela crotalária júncea e pelo guandu foi significativamente maior que a das demais leguminosas (Quadro 2). Esses resultados corroboram os de LAZZARINI NemE (1967), Souza (1953) e Alvarenga et al. (1995). A pro-
Quadro 2. Produção de fitomassa verde até o florescimento por adubos verdes plantados intercaladamente ao café Apoatã IAC 2258 (médias de cinco repetições)

\begin{tabular}{lcccc}
\hline \multirow{2}{*}{ Tratamento } & \multicolumn{4}{c}{ Fitomassa verde } \\
\cline { 2 - 5 } & 1991 & 1992 & 1993 & Total \\
\cline { 2 - 5 } & \multicolumn{4}{c}{ t.ha $^{-1}$} \\
\cline { 2 - 5 } Crotalária espectabilis & $25 \mathrm{~b}$ & $16 \mathrm{c}$ & $16 \mathrm{c}$ & $57 \mathrm{c}$ \\
Crotalária júncea & $103 \mathrm{a}$ & $69 \mathrm{a}$ & $66 \mathrm{~b}$ & $238 \mathrm{a}$ \\
Guandu & $82 \mathrm{a}$ & $76 \mathrm{a}$ & $126 \mathrm{a}$ & $284 \mathrm{a}$ \\
Mucuna-anã & $82 \mathrm{a}$ & $36 \mathrm{~b}$ & $22 \mathrm{c}$ & $140 \mathrm{~b}$ \\
Soja & $36 \mathrm{~b}$ & $11 \mathrm{c}$ & $20 \mathrm{c}$ & $67 \mathrm{c}$ \\
F & $18,9^{* *}$ & $24,0^{* *}$ & $29,6^{* *}$ & $39,6^{* *}$ \\
CV (\%) & 26,1 & 32,9 & 38,5 & 22,9 \\
\hline
\end{tabular}

Médias seguidas por letras distintas, na vertical, diferem, entre si, pelo teste de Duncan a 5\%. **: Significativo ao nível de 1\%.

dução total de fitomassa verde pela mucuna foi intermediária, sendo estatisticamente maior que a da soja e a da crotalária espectabilis.

O guandu foi a leguminosa que apresentou maior produção de fitomassa seca, seguido pela crotalária júncea que diferiu dos demais adubos verdes estudados (Quadro 3). Os resultados são semelhantes aos obtidos por Alvarenga et al. (1995) e diferem dos de SouzA (1953) apenas com relação à produção da fitomassa seca da crotalária júncea, que foi maior que a do guandu.

O total da fitomassa seca, produzida nos anos de 1991 a 1993 e a produzida apenas em 1993, correlacionou-se significativa e negativamente com a

Quadro 3. Produção de fitomassa seca até o florescimento por adubos verdes plantados intercaladamente ao café Apoatã IAC 2258 (médias de cinco repetições)

\begin{tabular}{lrrrr}
\hline Tratamento & \multicolumn{4}{c}{ Fitomassa seca } \\
\cline { 2 - 5 } & 1991 & 1992 & 1993 & Total \\
\cline { 2 - 5 } & & \multicolumn{5}{c}{ t.ha $^{-1}$} \\
Crotalária espectabilis & $4 \mathrm{~b}$ & $3 \mathrm{c}$ & $2 \mathrm{c}$ & $9 \mathrm{c}$ \\
Crotalária júncea & $32 \mathrm{a}$ & $20 \mathrm{~b}$ & $18 \mathrm{~b}$ & $70 \mathrm{~b}$ \\
Guandu & $38 \mathrm{a}$ & $29 \mathrm{a}$ & $60 \mathrm{a}$ & $127 \mathrm{a}$ \\
Mucuna-anã & $10 \mathrm{~b}$ & $5 \mathrm{c}$ & $4 \mathrm{c}$ & $19 \mathrm{c}$ \\
Soja & $8 \mathrm{~b}$ & $2 \mathrm{c}$ & $5 \mathrm{c}$ & $15 \mathrm{c}$ \\
F & $39,1^{* *}$ & $50,6^{* *}$ & $35,8^{* *}$ & $64,5^{* *}$ \\
CV (\%) & 30,5 & 31,9 & 50,4 & 29,0 \\
\hline
\end{tabular}

Médias seguidas por letras distintas, na vertical, diferem, entre si, pelo teste de Duncan a 5\%. **: Significativo ao nível de $1 \%$. 
produtividade do cafeeiro, obtendo-se, respectivamente, os coeficientes $r=-0,94(p<0,05)$ e $r=$ $-0,99(\mathrm{p}<0,01)$ (Figura 1). Isso sugere que a produção da fitomassa foi a responsável pela diminuição da produção do cafeeiro, provavelmente pela maior competição por água, luz e nutrientes que ocorreu nos tratamentos com maior produção de fitomassa. Deve-se, principalmente, ao guandu que permaneceu junto ao cafeeiro por 150 dias, enquanto as demais leguminosas, cerca de 90 dias apenas.

Os resultados obtidos para altura da planta e diâmetro do caule mostraram que essas variáveis foram influenciadas negativamente apenas pelo cultivo do guandu nas entrelinhas da cultura (Quadro 4). Excluindo-se a testemunha e corre-

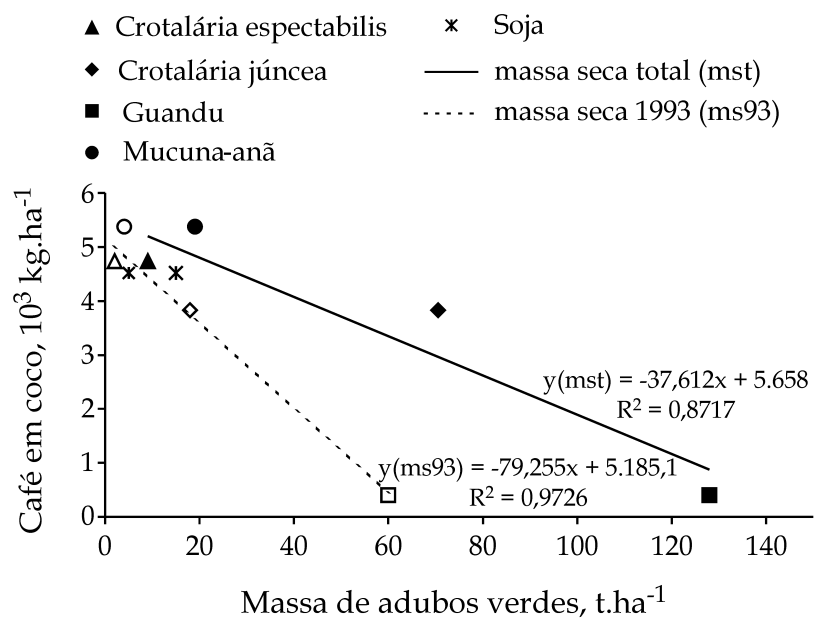

Figura 1. Produção de café Apoatã relacionada à massa seca de adubos verdes, total e a do ano de 1993 (símbolos vazios), incorporada no florescimento entre as linhas da cultura. lacionando-se esses dados com a produção de café (Quadro 1), obtiveram-se os coeficientes de correlação $r=0,56(p<0,05)$ e $r=0,91(p<0,05)$ respectivamente, indicando que a produção foi dependente do crescimento da planta.

A análise das amostras de solo coletadas em 1993 mostrou que, comparando-se com o tratamento testemunha, apenas a matéria orgânica do solo foi significativamente alterada pelo cultivo dos adubos verdes guandu e crotalária júncea nas entrelinhas do cafeeiro (Quadro 5). Esse aumento da matéria orgânica foi, provavelmente, resultante das maiores quantidades de fitomassa produzidas, tanto da parte aérea como das raízes, por essas duas culturas.

Quadro 4. Altura e diâmetro do caule de cafeeiros Apoatã IAC 2258 submetidos à semeadura intercalar de adubos verdes. Os dados foram obtidos em 1993 e são médias de cinco repetições

\begin{tabular}{lcc}
\hline Tratamento & $\begin{array}{c}\text { Altura } \\
\text { da planta }\end{array}$ & $\begin{array}{c}\text { Diâmetro } \\
\text { do caule }\end{array}$ \\
\cline { 2 - 2 } Crotalária espectabilis & $279,2 \mathrm{a}$ & $41,1 \mathrm{a}$ \\
\cline { 2 - 3 } Crotalária júncea & $281,8 \mathrm{a}$ & $38,4 \mathrm{a}$ \\
Guandu & $236,0 \mathrm{~b}$ & $24,9 \mathrm{~b}$ \\
Mucuna-anã & $273,8 \mathrm{a}$ & $36,3 \mathrm{a}$ \\
Soja & $291,5 \mathrm{a}$ & $39,4 \mathrm{a}$ \\
Testemunha & $287,1 \mathrm{a}$ & $37,3 \mathrm{a}$ \\
F & $6,19^{* *}$ & $10,63^{* *}$ \\
CV (\%) & 6,55 & 11,01 \\
\hline
\end{tabular}

Médias seguidas por letras distintas, na vertical, diferem entre si pelo teste de Duncan a 5\%. ${ }^{* *}$ : Significativo ao nível de $1 \%$.

Quadro 5. Análise química das amostras de solo após cultivo com adubos verdes por três anos consecutivos

\begin{tabular}{|c|c|c|c|c|c|c|c|c|c|c|}
\hline Tratamentos & $\mathrm{P}$ & M.O. & $\mathrm{pH}$ & K & $\mathrm{Ca}$ & $\mathrm{Mg}$ & S.B. & $\mathrm{H}+\mathrm{Al}$ & $\mathrm{T}$ & V \\
\hline & $\mathrm{mg}_{3} \mathrm{dm}^{-}$ & g.dm ${ }^{-3}$ & \multicolumn{7}{|c|}{$\mathrm{mmol}_{\mathrm{C}} \cdot \mathrm{dm}^{-3}$} & $\%$ \\
\hline Crotalária espectabilis & 11 & $1,5 \mathrm{ab}$ & 4,8 & 4,0 & 10,4 & 5,0 & 19,4 & 22,0 & 41,4 & 47 \\
\hline Crotalária júncea & 15 & $1,7 \mathrm{a}$ & 4,8 & 3,8 & 11,2 & 5,8 & 20,8 & 23,6 & 44,4 & 47 \\
\hline Soja & 9 & $1,3 \mathrm{~b}$ & 4,7 & 3,3 & 8,8 & 4,6 & 16,7 & 22,2 & 38,9 & 43 \\
\hline Guandu & 13 & $1,6 \mathrm{a}$ & 4,7 & 4,7 & 11,6 & 5,2 & 21,5 & 24,0 & 45,5 & 46 \\
\hline Mucuna-anã & 21 & $1,5 \mathrm{ab}$ & 4,7 & 3,7 & 10,4 & 4,2 & 18,3 & 24,4 & 42,7 & 43 \\
\hline Testemunha & 12 & $1,32 \mathrm{~b}$ & 4,6 & 3,9 & 10,0 & $4,6 \mathrm{~b}$ & 18,5 & 23,0 & 41,5 & 45 \\
\hline $\mathrm{F}$ & $1,07 \mathrm{~ns}$ & $2,69^{*}$ & $0,66 \mathrm{~ns}$ & $2,23 \mathrm{~ns}$ & $0,58 \mathrm{~ns}$ & $1,82 \mathrm{~ns}$ & $0,94 \mathrm{~ns}$ & $0,88 \mathrm{~ns}$ & $1,72 \mathrm{~ns}$ & $0,44 \mathrm{~ns}$ \\
\hline $\mathrm{CV}(\%)$ & 67,3 & 13,9 & 3,3 & 18,2 & 27,0 & 19,0 & 20,7 & 10,0 & 9,3 & 13,7 \\
\hline
\end{tabular}

Médias seguidas por letras distintas, na vertical, diferem entre si pelo teste de Duncan a 5\%. ns: Não significativo. *: Significativo ao nível de $5 \%$. 


\section{CONCLUSÕES}

1. O consórcio do cafeeiro com a soja, a mucunaanã e a crotalária espectabilis não diminuiu a produção do café Apoatã IAC 2258.

2. A produção do cafeeiro correlacionou-se inversamente com a produção de fitomassa seca produzida pelos adubos verdes e, positivamente, com a altura e o diâmetro do caule das plantas de café no ano da colheita.

\section{REFERÊNCIAS BIBLIOGRÁFICAS}

ALVARENGA, R.C.; COSTA, L.M. da; MOURA-FILHO, W.; REGAZZI, A.J. Características de alguns adubos verdes de interesse para a conservação e recuperação de solos. Pesquisa Agropecuária Brasileira, Brasília, v.30, n.2, p.175-185, 1995.

BATISTELA-SOBRINHO, J.; MATIELLO, J.B. Avaliação do sistema radicular de cafeeiros conilon em comparação com Catuaí e Mundo Novo - em Alta Floresta, MT. In: CONGRESSO BRASILEIRO DE PESQUISAS CAFEEIRAS, 14., 1987, s.p. (CD-room)

BERTONI, J.; LOMBARDI-NETO, F. Conservação do solo. 1. ed. Piracicaba: Livroceres, 1985. 392p.

DECHEN, S.C.F.; LOMBARDI-NETO, F.; CASTRO, O.M. Gramíneas e leguminosas e seus restos culturais no controle de erosão em latossolo roxo. Revista Brasileira de Ciência do Solo, Campinas, v.5, p.133-137, 1981.

FRAGA, C.G.; CONAGIN, A. Delineamentos e análises de experimentos com cafeeiros. Bragantia, Campinas, v.15, p.177-191, 1956.

FRANCO, C.M.; LAZZARINI, W. Ensaio de adubação mineral NPK e adubos verdes. In: LAZZARINI et al. Experimentação cafeeira, 1929-1963. Campinas: Secretaria da Agricultura do Estado de São Paulo - Instituto Agronômico, 1967. p.173-177.

FRANCO, C.M.; LAZZARINI, W.; CONAGIN, A.; REIS, A.J.; MORAES, F.R.P. de. Manutenção de cafezal com adubação exclusivamente mineral. Bragantia, Campinas, v.19, n.33, p.523-546, 1960.

IGUE, K. Dinâmica da matéria orgânica e seus efeitos na propriedade do solo. In: FUNDAÇÃOCARGILL. Adubação verde no Brasil. Campinas: Fundação Cargill, 1984. p.232-267.

INFORZATO, R.; REIS, A.J. Estudo comparativo do sistema radicular dos cafeeiros Bourbon amarelo e Mundo Novo. Bragantia, Campinas, v.22, n.2, p.741-750, 1963.

LAZZARINI, W.; NEME, A.N. Ensaio de adubação verde e química. In: LAZZARINI et al. Experimentação cafeeira, 1929-1963. Campinas: Secretaria da Agricultura do Estado de São Paulo - Instituto Agronômico, 1967. p.199-203.

LOMBARDI-NETO, F.; BERTONI, J.; BENATTI-JÚNIOR, R. Efeito de algumas práticas conservacionistas vegetativas na produção de café. In: CONGRESSO BRASI-
LEIRO DE CIÊNCIA DO SOLO, 15., 1975, Campinas. Anais... Campinas: Sociedade Brasileira de Ciência do Solo, 1976a. p.547-550.

LOMBARDI-NETO, F.; BERTONI, J.; BENATTI-JÚNIOR, R. Práticas conservacionista em cafezal e as perdas por erosão em solos podzolizados. In: CONGRESSO BRASILEIRO DE CIÊNCIA DO SOLO, 15., 1975, Campinas. Anais... Campinas: Sociedade Brasileira de Ciência do Solo, 1976b. p.559-562.

MALAVOLTA, E. Manual de química agrícola: adubos e adubação. São Paulo: Editora Agronômica Ceres, 1967. $606 \mathrm{p}$.

MATIELLO, J.B.; SAN JUAN, R.C.C.; SANTINATO, R. Mapeamento do sistema radicular do cafeeiro. In: CONGRESSO BRASILEIRO DE PESQUISAS CAFEEIRAS, 22., 1996, Águas de Lindóia. Trabalhos apresentados... Rio de Janeiro:CATI/MAA/PROCAFÉ, 1996. p.165-166.

MELLES, C.C.A; GUIMARÃES, P.T.G.; NACIF, A.P.; SILVA, C.M. da; CARVALHO, M.M. de; ANDRADE, M.A. de. Efeito de culturas intercalares na cultura do cafeeiro. In: CONGRESSO BRASILEIRO DE PESQUISAS CAFEEIRAS, 7., 1979, Araxá. Resumos... Rio de Janeiro: IBC/GERCA, 1979. p.174-175.

MELLES, C.C.A.;SILVA, C.M. de.Culturas intercalares. Informe Agropecuário, Belo Horizonte, v.4, n.44, p.70-71, 1978.

MIYASAKA, S.; CAMARGO, O.A.; CAVALIERI, P.A.; GODOY, I.J.; CURI, S.M.; LOMBARDI-NETO, F.; MEDINA, J.C.; CERVELLINI, G.S.; BULISANI, E.A. Adubação verde e rotação de culturas no Estado de São Paulo. Campinas, Fundação Cargill, 1983. 138p.

PEDRO-JÚNIOR, M.J.; BULISANI, E.A.; POMMER, C.V.; PASSOS, E.A.; GODOY, I.J.; ARANHA, C. Instruções agrícolas para o Estado de São Paulo. 4.ed. Campinas, Instituto Agronômico, 1987. 231p.

RAIJ, B. van; QUAGGIO, J.A. Métodos de análises de solos para fins de fertilidade. Campinas: Instituto Agronômico, 1983. 31p. (Boletim Técnico, 81)

REIS, A.J.; ARRUDA, H.V. Alguns resultados sobre técnicas culturais do cafeeiro na região de Ribeirão Preto. In: CONGRESSO BRASILEIRO DE PESQUISAS CAFEEIRAS, 2., 1974, Poços de Caldas. Resumos... Rio de Janeiro: IBC, 1974. p.324-326.

REIS, A.J.; ARRUDA, H.V. Efeito depressivo da soja perene como adubo verde para cafezal. In: CONGRESSO BRASILEIRO DE PESQUISAS CAFEEIRAS, 8., 1980, Campos do Jordão. Anais... IBC-GERCA. p.101-103.

SOUZA, D.F. A adubação verde e o problema dessa prática na lavoura canavieira paulista. Piracicaba, 1953. 47p. Tese (Doutorado) - Escola Superior de Agricultura Luiz de Queiroz-USP.

VEGRO, C.L.R.; CAMARGO, A.P. de; OLIVEIRA, E.G. de; MORICOCHI, L.; MARTIN, N.B.; THOMAZIELLO, R.A. Café Robusta: uma alternativa para a cafeicultura paulista. Informações Econômicas, São Paulo, v.26, n.7, p.66-70, 1996. 